Psychological Medicine, 1982, 12, 701-704

Printed in Great Britain

\title{
EDITORIAL
}

\section{Use of the anticonvulsant carbamazepine in primary and secondary affective illness: clinical and theoretical implications ${ }^{1}$}

Carbamazepine is a tricyclic compound bearing some resemblance to imipramine, with an interesting spectrum of clinical efficacy in paroxysmal pain syndromes, paroxysmal neural discharges of seizure disorders, and in disorders of mood and behaviour. Although still somewhat controversial, increasing evidence is emerging that carbamazepine is efficacious in the treatment of mood and behavioural disturbances associated with psychomotor seizures or complex partial seizures (Dalby, 1971, 1975). Dalby's observations in 1971 and in his review in 1975 indicate that, in both open and controlled clinical trials, there is evidence of the psychotropic effect of carbamazepine which, in some instances, appears to occur independently of improvement in the underlying seizure disorder itself. While some investigators have argued that the positive psychotropic effects are either related to better seizure control or to the substitution of carbamazepine for other anticonvulsants, these do not appear to be sufficient explanations. In controlled clinical studies, positive effects on mood and behaviour are noted in both patient (Dodrill \& Troupin, 1977) and normal volunteer populations (Thompson et al. 1980). Thompson, for example, noted significant and dose-related impairment of cognitive functioning in volunteers treated with phenytoin, but non-significant effects during carbamazepine administration. Moreover, the patients on carbamazepine reported themselves as more active, less tired, and less depressed, in contrast to those on phenytoin who reported themselves as more depressed, less active, and significantly more fatigued (Thompson et al. 1980).

Carbamazepine is a drug of choice in the treatment of complex partial seizures and other seizure disorders thought to be related in part to temporal lobe and limbic mechanisms. In parallel, there is clear-cut laboratory evidence that carbamazepine is more effective in suppressing seizures derived from temporal lobe and limbic sites than those from other neocortical areas. Albright \& Burnham, for example, reported that carbamazepine was the most effective anticonvulsant in suppressing after discharges associated with amygdala compared with neocortical kindling (Albright \& Burnham, 1980). Thus, carbamazepine has an interesting clinical and laboratory profile of relatively greater efficacy in suppressing limbic compared with cortical excitability. It is also effective in suppressing the progressive development of seizures, such as those manifest in kindling (Babington \& Horovitz, 1973; Wada, 1977; Wada et al. 1976).

Two groups of Japanese investigators had reported in open clinical trials that carbamazepine was also useful in the treatment of patients with manic-depressive illness not associated with seizure disorder (Takezaki \& Hanaoka, 1971; Okuma et al. 1973). In the light of these observations and the reports of carbamazepine's efficacy in affective illness occurring in association with epilepsy (Dalby, 1971, 1975) as well as its ability to suppress limbic system excitability and to inhibit amygdala kindling (Albright \& Burnham, 1980; Babington \& Horovitz, 1971; Wada, 1977; Wada et al. 1976), we were encouraged to proceed with the first controlled clinical trials of carbamazepine in patients with manic and depressive illness (Post et al. 1978, 1982a, b; Ballenger \& Post, 1978, 1980).

Using a double-blind placebo-controlled design, we noted substantial antimanic efficacy when carbamazepine was substituted for placebo. Relapses occurred following placebo substitution, and patients again improved when carbamazepine was reinitiated. Patients were treated with an average dose of approximately $1000 \mathrm{mg} /$ day, with blood levels between 6 and $12 \mathrm{ug} / \mathrm{ml}$ (Post et al. 1978, 1982 a, b; Ballenger \& Post, 1978, 1980). Okuma and associates (1979) have compared carbamazepine with chlorpromazine in the treatment of acute manic patients, using a double-blind methodology.

\footnotetext{
- Address for correspondence: Dr R. M. Post, Biological Psychiatry Branch, Building 10, Room 3N212, National Institute of Mental Health. Bethesda MD 20205, USA.
} 
They found that $70 \%$ of patients showed marked to moderate improvement with carbamazepine compared with $60 \%$ of those treated with chlorpromazine. The incidence of side-effects, particularly drowsiness, was significantly lower during carbamazepine than with chlorpromazine treatment. We and Okuma have not observed Parkinsonian side-effects occurring during the course of carbamazepine treatment, although occasional dystonias or dyskinesias have been reported in the neurological literature. Tardive dyskinesia has not been reported as a side-effect of carbamazepine treatment in epileptic patients, many of whom have been maintained on the drug for long periods of time. Moreover, unlike traditional neuroleptics, carbamazepine does not acutely block cocaine (Post et al. $1982 b$ ) or amphetamine-induced (Koella et al. 1975) hyperactivity and does not produce HVA elevations in the CSF of our psychiatric patients (Post et al. 1982b). Thus, it is likely that the mechanisms underlying the antimanic effects of carbamazepine are different from those of traditional neuroleptics and are not the result of direct dopamine receptor blockade. If this finding is confirmed, it would appear to be of theoretical interest as well as of clinical importance.

In our first 25 depressed patients, both bipolar and unipolar, we observed a $48 \%$ incidence of good to moderate antidepressant responses (Post et al. 1982a, b). In those patients who showed initial improvement, mild relapses were often observed following placebo substitution, while depression was not exacerbated in those patients who did not initially improve. These data further suggest that the improvement in depression was carbamazepine-related and that drug discontinuation was not associated with a non-specific withdrawal syndrome, but rather with some exacerbation of original symptomatology. In contrast to the rapid onset of antimanic effects and improvement in sleep disturbance noted in both manic and depressed patients within the first week, antidepressant responses did not generally occur until the beginning of the third week of treatment (Post et al. $1982 b)$.

We have also observed substantial prophylactic responses to carbamazepine in 6 of 7 patients who were previously non-responsive to treatment with lithium carbonate (Post et al. 1982b). Improvement was particularly notable in 2 patients with severe and fulminant rapidly cycling manic-depressive illness who had required essentially continuous state hospitalization for several decades prior to admission to NIMH. These data suggest the potential usefulness of carbamazepine for treatment-resistant and rapidly cycling patients. Our findings parallel the early observations of Okuma and associates (1973) of a prophylactic effect of carbamazepine in $74 \%$ of patients suffering from manic episodes and $52 \%$ of patients with depressive episodes. A more recent clinical trial (Okuma et al. 1981) in 12 manic-depressive patients, using a double-blind methodology, indicated an effective rate for one year of carbamazepine prophylaxis at $60 \%$, compared with only $22.2 \%$ in the placebo group $(P<0 \cdot 10)$.

We have observed positive responses to carbamazepine in patients with a classical presentation of manic or depressive symptoms, as well as in several patients with schizo-affective illness (Post et al. 1982 b). One patient with a recurrent confusional psychosis also showed a positive response to carbamazepine. Recently, in an open study, Folks et al. (1982) reported improvement in 8 of 10 patients with bipolar $(N=4)$, schizo-affective $(N=3)$ and affective syndromes associated with evidence of a CNS disorder $(N=3)$. Stevens et al. (1979) reported exacerbation of psychotic symptomatology when carbamazepine was added to high-dose neuroleptic treatment in schizophrenics. However, we have not observed this in our patients with affective or schizo-affective illness, some of whom show further improvement when neuroleptics are added to carbamazepine (Ballenger \& Post, 1978; Post et al. 1982b).

Thus, the early evidence is highly suggestive that carbamazepine may prove useful both in the treatment of a subgroup of patients with classical primary affective illness, as well as in a subgroup of patients with schizo-affective or more atypical presentations. Further studies are required to delineate clinical and biological markers of response to carbamazepine and to study whether these patients overlap with or represent a separate subgroup of patients responsive to routine psychotropic medications such as lithium carbonate, tricyclic antidepressants or neuroleptics. Further studies of carbamazepine would also appear indicated because of its different profile of side-effects compared with routine psychotropic drugs. As noted above, it does not appear to possess the liabilities of 
neuroleptics in producing either a Parkinsonian or tardive dyskinesia syndrome or of exacerbating depressive phases of the illness, as has been reported for the antipsychotic agents (Kukopulos $e t$ al. 1980). Similarly, it would not appear to possess the liability of routine tricyclic antidepressants to increase the incidence of exacerbating manic episodes. In addition, in contrast to lithium carbonate, carbamazepine not only does not induce the diabetes insipidus (DI) syndrome, but it has been utilized to treat it (Wales, 1975; Maffy, 1977; Stevens et al. 1978). Early observations do not support the view that carbamazepine will reverse lithium-induced DI when the two drugs are used concomitantly (Ghose, 1978), but substitution of carbamazepine for lithium may alleviate the problems of DI. Recent data from our laboratory suggest that carbamazepine may have direct effects at the vasopressin receptor (Berrettini et al. 1981). It is also possible that some of the positive effects of carbamazepine on mood and cognition could be related to its vasopressin agonist-like effects.

Carbamazepine also has interesting effects on noradrenergic mechanisms both blocking re-uptake and inhibiting stimulated-induced release (Purdy et al. 1977). Recent studies suggest that it may decrease GABA turnover (Bernasconi \& Martin, 1979), although CSF GABA levels in affectively ill patients are unaffected (Post et al. 1980). While it is highly effective in the treatment of a variety of pain syndromes, carbamazepine does not significantly affect CSF opiate binding activity (Post et al. 1981 a). Rubinow and associates (1982) have reported that carbamazepine significantly decreases CSF somatostatin. Further laboratory and clinical investigations are needed to delineate the major mechanisms of action of carbamazepine in relation to its psychotropic, anticonvulsive, and antinociceptive effects.

Recently, Emrich and associates (1980) reported that another anticonvulsant, valproic acid, was useful in the treatment of a small number of patients with treatment-resistant affective illness. These findings, taken in conjunction with observations of carbamazepine's efficacy, raise the question of whether a series of anticonvulsant compounds may not have positive psychotropic effects in some patients with affective illness. We are currently studying whether patients who respond to carbamazepine will also respond to other anticonvulsants. In our first patient, who was an unequivocal carbamazepine responder on two occasions, no antimanic response was in evidence when she was crossed over on a double-blind basis to either phenytoin or valproic acid (Post et al. $1982 a$; unpublished data with W. Berrettini). The selectivity of response to anticonvulsant agents may yield further clues regarding their relative regional and biochemical mechanisms of action. In the light of the emerging evidence of positive responses to carbamazepine in primary and secondary affective syndromes and also perhaps to valproic acid in some individuals (Emrich et al. 1980), one might ask why seizures induced by electroconvulsive therapy are also efficacious in the treatment of manic and depresssive illness. A recent study in our laboratory, in collaboration with F. Putnam and N. Contel, suggests a possible explanation of the paradox that both seizures and anticonvulsant agents might be useful in the treatment of affective illness. We have observed that electroconvulsive seizures (ECS) markedly inhibited the development and maintenance of amygdala kindled seizures (Post et al. $1981 \mathrm{~b}$ ). ECS six hours prior to amygdala kindling inhibited the development of seizures when compared with sham ECS animals. In a further study, seven daily ECS compared with sham treatment suppressed amygdala kindled seizures for up to five days following the resumption of kindling. These data raise the possibility that the limbic anticonvulsant effects of electroconvulsive seizures could be, in part, related to their usefulness in the treatment of affectively ill patients.

We would encourage cautious clinical investigative work to delineate further clinical and biological markers of carabamazepine response, as well as approaches to underlying biochemical and physiological mechanisms of action. Although the drug in the United States is not approved by the Food and Drug Administration for use in patients with affective illness, it is available on the basis of a physician's discretion. Considerable experience has been gleaned in the long-term use of carbamazepine in patients with epilepsy (Penry \& Daly, 1975). In this area, although there are rare reports of the development aplastic anaemia (Piscotta, 1975), recent experience has documented the safety of the drug and its record of good patient acceptance compared with other anticonvulsant agents. Ongoing studies of carbamazepine suggest the possibility that not only will it prove to be a new and clinically important form of treatment, particularly for patients not responsive or unable 
to tolerate lithium carbonate, but also the drug might provide additional information for the understanding of the mechanisms underlying the major affective disorder (Post et al. 1982b).

\section{REFERENCES}

Albright, P. S. \& Burnham, W. M. (1980). Development of a new pharmacological seizure model: effects of anticonvulsants on cortical- and amygdala-kindled seizures in the rat. Epilepsia 21, $681-689$.

Babington, R. G. \& Horovitz, Z. P. (1973). Neuropharmacology of SQ 10,996 , a compound with several therapeutic indications. Archives Internationale de Pharmacodynamie 202, 106-118.

Ballenger, J. C. \& Post, R. M. (1978). Therapeutic effects of carbamazepine in affective illness: a preliminary report. Communications in Psychopharmacology 2, 159-175.

Ballenger, J. C. \& Post, R. M. (1980). Carbamazepine (Tegretol) in manic-depressive illness: a new treatment. American Journal of Psychiatry 137, 782-790.

Bernasconi, R. \& Martin, P. (1979). Effects of antileptic drugs on the GABA turnover rate. Naunyn-Schmiedebergs Archiv für experimentalle Pathologie und Pharmakologie (suppl) 307, R63, Abstract 251 .

Berrettini, W. H., Post, R. M., Worthington, E. K. \& Casper, J. B. (1981). Human platelet vasopressin receptors. Life Sciences $\mathbf{3 0}$, 425-432.

Dalby. M. A. (1971). Antiepileptic and psychotropic effect of carbamazepine (Tegretol) in the treatment of psychomotor epilepsy. Epilepsia 12, 325-334.

Dalby, M. A. (1975). Behavioral effects of carbamazepine. In Complex Partial Seizures and Their Treatment: Advances in Neurology, Vol. II (ed. J. K. Penry and D. D. Daly), pp. 331-343. Raven Press: New York

Dodrill. C. B. \& Troupin, A. S. (1977). Psychotropic effects of carbamazepine in epilepsy: a double-blind comparison with phenytoin. Neurology 27, 1023-1028.

Emrich, H. M., von Zerssen, D., Kissling, W., Moller, H.-J. \& Windorfer, A. (1980). Effect of sodium valproate in mania. The GABA-hypothesis of affective disorders. Archiv für Psychiatrie und Nervenkrankheiten 229, 1-16.

Folks, D. C., King, L. D., Dowdy, S. B., Petrie, W. M., Jack, R. A. Koomen, J. C., Swenson, B. R. \& Edwards, P. (1982). Carbamazepine treatment of selected affectively disordered inpatients. American Journal of Psychiatry 139, 115-117.

Ghose, K. (1978). Effect of carbamazepine in polyuria associated with lithium therapy. Pharmakopsychiatrie und Neuropsychopharmakologie 11, 241-245.

Koella, W. P., Levin, P. \& Baltzer, V. (1975). The pharmacology of carbamazepine and some other anti-epileptic drugs. In Epileptic Seizures - Behavior - Pain (ed. W. Birkmayer), pp. 32-50. Hans Huber: Bern.

Kukopulos, A., Reginaldi, D., Laddomada, P., Floris, G., Serra, G. \& Tondo, L. (1980). Course of the manic-depressive cycle and changes caused by treatments. Pharmakopsychiatrie 13, 156-167.

Maffly, R. H. (1977). Diabetes insipidus. In Disturbances in Body Fluid Osmolality (ed. T. E. Andredi), pp. 285-308. American Physiological Society: Bethesda, MD.

Okuma, T., Kishimoto, A., Inouye, K., Matsumoto, H., Ogura, A., Matsushita, T., Naklao, T. \& Ogura, C. (1973). Anti-manic and prophylactic effects of carbamazepine on manic-depressive psychosis. Folia psychiatrica et neurologica Japonica 27, 283-297.

Okuma, T., Inanaga, K., Otsuki, S., Sarai, K., Takahashi, R., Hazama, H., Mori, A. \& Watanabe, M. (1979). Comparison of the antimanic efficacy of carbamazepine and chlorpromazine: a double-blind controlled study. Psychopharmacology 66, 211-217.

Okuma, T., Inanaga, K., Otsuki, S.. Sarai. K., Takahashi, R., Hazama, H., Mori, A. \& Watanabe. M. (1981). A preliminary double-blind study of the efficacy of carbamazepine in prophylaxis of manic-depressive illness. Psychopharmacology 73, 95.96
Penry, J. K. \& Daly, D. D. (1975). Complex Partial Seizures and Their Treatment: Advances in Neurology, Vol. 11. Raven Press: New York.

Piscotta, A. V. (1975). Hematologic toxicity of carbamazepine. In Complex Partial Seizures and their Treatment: Advances in Neurology, Vol. 11 (ed. J. K. Penry and D. D. Daly), pp. 355366. Raven Press: New York.

Post, R. M., Ballenger, J. C., Reus, V. I., Lake, C. R., Lerner, P. \& Bunney, W. E. Jr (1978). Effects of carbamazepine in mania and depression. Presented at the Scientific Proceedings of the $131 \mathrm{st}$ Annual Meeting of the American Psychiatric Association, Atlanta, May 1978, New Research Abstracts No. 7.

Post, R. M., Ballenger, J. C., Hare. T. A. \& Bunney, W. E. Jr (1980). Lack of effect of carbamazepine on gamma-aminobutyric acid levels in cerebrospinal fluid. Neurology 30, 10081011.

Post, R. M., Pickar, D., Naber, D., Ballenger, J. C., Uhde, T. W. \& Bunney, W. E. Jr (198Ia). Effect of carbamazepine on CSF opioid activity: relationship to antidepressant response. Psychiatry Research 5, 59-61.

Post, R. M., Putnam, F. W. \& Contel, N. R. (1981 b). Electroconvulsive shock inhibits amygdala kindling. Society for Neuroscience Abstracts, 1Ith Annual Meeting, Abstract No. 187.13, 7, 587.

Post, R. M., Ballenger, J. C., Uhde, T. W., Chatterji, D. C. \& Bunney, W. E. Jr (1982a). Efficacy of the temporal-lobe limbic anticonvulsant carbamazepine in manic and depressive illness. In Proceedings of the 3rd World Congress of Biological Psychiatry, Stockholm, June 1981 (ed. B. Jansson, C. Perris and G. Struwe). Elsevier: Amsterdam.

Post, R. M., Ballenger, J. C., Uhde, T. W. \& Bunney, W. E. Jr (1982b). Efficacy of carbamazepine in manic-depressive illness implications for underlying mechanisms. In Neurobiology of the Mood Disorders (ed. R. M. Post and J. C. Ballenger). Williams and Wilkins: Baltimore (in the press).

Purdy, R. E., Julien, R. M., Fairhurst, A. S. \& Terry, M. D. (1977). Effect of carbamazepine on the in vitro uptake and release of norepinephrine in adrenergic nerves of rabbit aorta and in whole brain synaptosomes. Epilepsia 18, 251257.

Rubinow, D. R., Gold, P., Post, R. M., Ballenger, J. C. \& Reichlin, S. (1982). Somatostatin in affective illness and normal volunteers. In Neurobiology of the Mood Disorders (ed. R. M. Post and J. C. Ballenger). Williams and Wilkins: Baltimore (in the press).

Stevens, J. R., Bigelow, L., Denney, D., Lipkin, J., Livermore, A., Ranscher, F. \& Wyatt, R. J. (1979). Telemetered EEG -EOG during psychiatric behaviors of schizophrenics. Archives of General Psychiatry 36, 251 262.

Stephens, W. P., Coe, J. Y. \& Baylis, P. H. (1978). Plasma arginine vasopressin concentrations and antidiuretic action of carbamazepine. British Medical Journal i, $1445-1447$.

Takezaki, H. \& Hanaoka, M. (1971). The use of carbamazepine (Tegretol) in the control of manic-depressive psychosis and other manic, depressive states (in Japanese). Sheishin-igaku 13, 173183.

Thompson, P., Huppert, F. \& Trimble, M. (1980). Anticonvulsant drugs, cognitive function and memory. Acta neurologica scandinavica (suppl 80) 62, 75-81.

Wada, J.A. (1977). Pharmacological prophylaxis in the kindling model of epilepsy. Archives of Neurology 34, 389.395.

Wada, J. A., Sato, M., Wake, A., Green, J. R. \& Troupin, A. S. (1976). Prophylactic effects of phenytoin, phenobarbital, and carbamazepine examined in kindled cat preparation. Archives of Neurology 33, 426-434.

Wales, J. K. (1975). Treatment of diabetes insipidus with carbamazepine. Lancet ii, 948-951. 